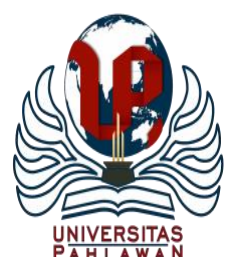

Jurnal Abdidas Volume 2 Nomor 4 Tahun 2021 Halaman 936-943

JURNAL ABDIDAS

http://abdidas.org/index.php/abdidas

\title{
Penyuluhan Pemanfaatan Sampah Daun dan Limbah Pertanian Menjadi Briket Biorang sebagai Sumber Energi Terbaru Ramah Lingkungan
}

\author{
Slamet Mardiyanto Rahayu ${ }^{1 凶}$, Rosalina Edy Swandayani ${ }^{2}$, Arista Suci Andini ${ }^{3}$, Hasan Basri ${ }^{4}$, \\ Syuhriatin $^{5}$, Baiq Diah Fitasari ${ }^{6}$, Meilinda Pahriana Sulastri ${ }^{7}$, Diah Meidatuzzahra $^{8}$ \\ Biologi, Fakultas MIPA, Universitas Islam Al-Azhar, Indonesia ${ }^{1,2,3,4,5,6,7,8}$ \\ E-mail: slamet.mardiyantorahayu84@gmail.com ${ }^{1}$
}

\begin{abstract}
Abstrak
Tanaman di lahan pertanian dan pekarangan di Desa Peresak terus menerus menghasilkan limbah berupa limbah daun dan limbah pertanian. Namun, sampai saat ini limbah daun tersebut hanya dibakar sehingga dapat menimbulkan pencemaran udara. Padahal serasah daun dan limbah pertanian berpotensi untuk dikembangkan sebagai sumber energi terbarukan yang ramah lingkungan. Berdasarkan hal tersebut maka dilakukan kegiatan pengabdian kepada masyarakat berupa penyuluhan pemanfaatan limbah daun sebagai briket bioarang dengan metode ceramah. Hasil pengabdian masyarakat ini berupa meningkatnya pengetahuan dan keterampilan masyarakat dalam memanfaatkan limbah daun dan limbah pertanian menjadi briket sebagai sumber energi terbarukan yang ramah lingkungan. Hal ini terbukti dari banyaknya masyarakat yang antusias saat sesi diskusi (tanya jawab). Setelah kegiatan ini maka dapat disimpulkan bahwa perlu dilakukan pelatihan pembuatan briket bioarang kepada masyarakat Desa Peresak.
\end{abstract}

Kata kunci: penyuluhan, briket, Desa Peresak

Abstract

Plants on agricultural land and yards in Peresak Village continuously produce waste in the form of leaf waste and agricultural waste. However, until now, the leaf waste is only burned so that it can cause air pollution. Whereas leaf litter and agricultural waste have the potential to be developed as an environmentally friendly renewable energy source Based on this, community service activities were carried out in the form of counseling the use of leaf waste as biochar briquettes with the lecture method. The results of this community service are in the form of increasing community knowledge and skills in utilizing leaf waste and agricultural waste into briquettes as an environmentally friendly renewable energy source. This is evident from the number of people who are enthusiastic during the discussion session (question and answer). After this activity, it can be concluded that it is necessary to conduct training on making bio-charcoal briquettes to the Peresak Village community.

Keywords: socialization, briquettes, Peresak village

Copyright (c) 2021 Slamet Mardiyanto Rahayu, Rosalina Edy Swandayani, Arista Suci Andini, Hasan Basri, Syuhriatin, Baiq Diah Fitasari, Meilinda Pahriana Sulastri, Diah Meidatuzzahra

$\triangle$ Corresponding author

Address : Universitas Islam Al-Azhar

Email : slamet.mardiyantorahayu84@gmail.com

ISSN 2721-9224 (Media Cetak)

DOI : https://doi.org/10.31004/abdidas.v2i4.396

ISSN 2721- 9216 (Media Online) 
937 Penyuluhan Pemanfaatan Sampah Daun dan Limbah Pertanian Menjadi Briket Bioarang sebagai Sumber Energi Terbaru Ramah Lingkungan - Slamet Mardiyanto Rahayu, Rosalina Edy Swandayani, Arista Suci Andini, Hasan Basri, Syuhriatin, Baiq Diah Fitasari, Meilinda Pahriana Sulastri, Diah Meidatuzzahra

DOI: https://doi.org/10.31004/abdidas.v2i4.396

\section{PENDAHULUAN}

Kebutuhan energi makin meningkat seiring dengan perkembangan zaman dan pertumbuhan jumlah penduduk, energi diperlukan untuk kegiatan industri, jasa, perhubungan, dan rumah tangga. Saat ini Bahan Bakar Minyak (BBM) makin langka dan harganya makin mahal sehingga menimbulkan dampak sosial ekonomi kepada masyarakat konsumen. Pemanfaatan bahan organik sebagi pengganti penghasil kalor merupakan hal yang tepat. Karena bahan organik dipastikan selalu dapat diproduksi ulang oleh manusia.

Energi alternatif merupakan pilihan untuk mengatasi krisis energi, misalnya dengan biomassa yang potensial untuk dikembangkan menjadi energi terbarukan. Menurut Zamirza (2011), biomassa merupakan bahan yang dapat diperoleh dari tanaman baik secara langsung maupun tidak langsung dan dimanfaatkan sebagai energi atau bahan dalam jumlah besar dan disebut juga sebagai fitomassa dan sering diterjemahkan sebagai bioresource atau sumber daya yang diperoleh dari bahan hayati.

Pengembangan energi terbarukan dapat dilakukan melalui Clean Development Mechanism (CDM). CDM ini mengembangkan konversi biomassa menjadi bahan bakar atau sumber energi dan pembersihan lingkungan (Hadiwiyoto, 2009). Limbah biomassa digunakan sebagai salah satu sumber energi alternatif karena ketersediaan bahan yang berlimpah, murah, serta terbarukan (renewable).

Desa Peresak yang merupakan salah satu desa di Kecamatan Narmada, Kabupaten Lombok
Barat yang keadaan geografisnya menguntungkan. Tanah yang subur serta cadangan air yang melimpah merupakan potensi yang baik sebagai lahan pertanian berupa tanaman pangan, hortikultura, perkebunan, dan kehutanan. Lahan pertanian tersebut terutama untuk tanaman pangan yang mampu memberikan manfaat sangat besar untuk kesejahteraan hidup. Tanah yang subur di Desa Peresak juga berpotensi dalam pengembangan lahan pekarangan di sekitar rumah penduduk untuk ditanami berbagai tanaman pangan, tanaman obat, hortikultura, dan lain-lain.

Bahan-bahan organik dapat ditemukan di lingkungan sekitar, misalnya pada lahan-lahan subur dan lahan pertanian. Lahan pertanian masih banyak ditemukan di area pedesaan (Sumaryati, 2017). Salah satu desa yang memiliki area persawahan yang luas adalah Desa Setiling. Kebanyakan lahan pertanian di Desa Peresak ditanami dengan tanaman pangan dan didominasi oleh padi, karena makanan pokok masyarakat Indonesia adalah beras. Sekam adalah bagian terluar dari butir padi yang merupakan hasil samping saat proses penggilingan padi. Pada proses penggilingan padi, sekam akan terpisah dari butir beras dan menjadi bahan sisa atau limbah penggilingan. Kadar sekam adalah $20-30 \%$ dari bobot gabah yang digiling, dedak/abu $15 \%$, dan beras giling 50- 53,5\% (Hambali dkk., 2007). Daerah dengan penduduk padat (pemukiman, perkotaan) yang area terbukanya tinggal sedikit, dirasakan bahwa sampah menjadi problem tersendiri (Suyono dan Budiman, 2010). Permasalahan sampah di suatu kawasan meliputi 
938 Penyuluhan Pemanfaatan Sampah Daun dan Limbah Pertanian Menjadi Briket Bioarang sebagai Sumber Energi Terbaru Ramah Lingkungan - Slamet Mardiyanto Rahayu, Rosalina Edy Swandayani, Arista Suci Andini, Hasan Basri, Syuhriatin, Baiq Diah Fitasari, Meilinda Pahriana Sulastri, Diah Meidatuzzahra

DOI: https://doi.org/10.31004/abdidas.v2i4.396

tingginya laju timbulan sampah, kepedulian masyarakat yang masih rendah sehingga suka berperilaku membuang sampah sembarangan, keengganan untuk membuang sampah pada tempat yang sudah disediakan. Perilaku yang buruk ini seringkali menyebabkan bencana di musim hujan karena drainase tersumbat sampah sehingga terjadi banjir (Hardiatmi, 2011).

Produksi padi dalam jumlah besar akan menghasilkan sekam padi yang merupakan salah satu bentuk limbah pertanian yang selama ini hanya digunakan sebagai media tanam atau dibuang dan dibakar sebagai sampah. Sebagai bahan biomassa, arang sekam padi merupakan sumber karbon potensial yang dapat dimanfaatkan sebagai bahan bakar dalam skala besar sehingga dapat menjadi salah satu sumber energi alternatif pengganti bahan bakar minyak (BBM) (Yuliah dkk., 2017).

Berangkat dari keprihatinan bahwa semakin hari jumlah produksi sampah semakin meningkat, akibat dari pencemaran sampah tersebut keseimbangan lingkungan terganggu, misalnya terjangkitnya penyakit menular (Sudiran, 2005). Penanggulangan sampah umumnya hanya dengan cara dibakar percuma, hal tersebut karena tidak adanya pengetahuan warga mengenai alternatif untuk mengolah sampah padat (Riswan, 2011), sehingga dicarilah alternatif penanganan sampah yaitu pembakaran pirolisis dari sampah organik. Proses ini akan menghasilkan padatan (char) berupa arang dan berupa cairan (tar). Char dapat diproses menjadi briket bioarang (Archenita dkk., 2010). Pada setiap daun terdapat bermacam- macam unsur kimia, seperti unsur karbon dan air. Saat daun masih muda berwarna hijau dan tumbuh pada ranting-ranting pohon dengan kandungan air yang masih banyak. Saat daun sudah mulai menguning kemudian mengering lalu jatuh maka kadar air dalam daun sudah berkurang sehingga akan lebih mudah untuk dibakar dan dijadikan arang (Yustinah dan Hartin, 2011).

Tanaman yang ada di lahan pertanian maupun lahan pekarangan di Desa Peresak secara kontinu menghasilkan limbah berupa sampah daun dan limbah pertanian, berupa sekam padi dan tongkol jagung. Akan tetapi sampai saat ini, sampah daun tersebut hanya dibakar saja sehingga dapat menimbulkan pencemaran udara. Padahal sampah daun tersebut berpotensi untuk dikembangkan sebagai sumber energi terbarukan ramah lingkungan.

Briket adalah bahan bakar padat yang dapat digunakan sebagai sumber energi alternatif yang mempunyai bentuk tertentu. Pemilihan proses pembriketan tentunya harus mengacu pada segmen pasar agar dicapai nilai ekonomi, teknis dan lingkungan yang optimal. Pembriketan bertujuan untuk memperoleh suatu bahan bahar berkualitas yang dapat digunakan untuk semua sektor sebagai sumber energi pengganti (Himawanto, 2003).

Sumber energi alternatif ini dapat memberikan kontribusi terhadap bauran energi primer sebagai pengganti batubara apabila diolah secara optimal. Pengolahan arang sekam. padi menjadi briket merupakan salah satu cara pengemasan sekam padi yang efektif. Briket arang sekam padi dapat menyimpan energi kalor rata-rata 
939 Penyuluhan Pemanfaatan Sampah Daun dan Limbah Pertanian Menjadi Briket Bioarang sebagai Sumber Energi Terbaru Ramah Lingkungan - Slamet Mardiyanto Rahayu, Rosalina Edy Swandayani, Arista Suci Andini, Hasan Basri, Syuhriatin, Baiq Diah Fitasari, Meilinda Pahriana Sulastri, Diah Meidatuzzahra

DOI: https://doi.org/10.31004/abdidas.v2i4.396

sebesar $4384.043 \mathrm{~kJ} / \mathrm{kg}$ (Yuliah, 2017). Apabila limbah pertanian berupa sekam padi tersebut dapat dimanfaatkan sebagai penghasil kalor, maka masyarakat Desa Setiling dapat lebih menghemat penggunaan minyak bumi dan gas alam sebagai bahan bakar.

Manajemen dalam pengelolaan sampah yang baik perlu ditingkatkan dengan saling bekerja sama dan saling mendukung dengan pihak lain yang memiliki kontribusi dalam masalah sampah (Suprapto, 2005). Pengelolaan limbah domestik harus dilakukan secara terpadu oleh semua pihak, tidak hanya pemerintah, masyarakat, LSM, dan perguruan tinggi (Sudarwanto, 2010). Berdasarkan hal tersebut, perlu dilakukan penyuluhan pemanfaatan sampah daun dan limbah pertanian menjadi briket bioarang sebagai sumber energi terbarukan ramah lingkungan di Desa Peresak, Kecamatan Narmada, Kabupaten Lombok Barat.

\section{METODE}

Kegiatan pengabdian kepada masyarakat berupa penyuluhan pemanfaatan sampah daun dan limbah pertanian menjadi briket bioarang sebagai sumber energi terbarukan ramah lingkungan di Desa Peresak, Kecamatan Narmada, Kabupaten Lombok Barat dilaksanakan pada hari Senin tanggal 7 Juni 2021. Penyuluhan adalah suatu edukasi dalam aspek promotif untuk meningkatkan pengetahuan dan memperbaiki perilaku sasaran serta dapat menerapkan perilaku sehat dalam kehidupan sehari-hari. Kegiatan pengabdian masyarakat ini dilakukan melalui penyuluhan metode kelompok melalui ceramah. Ceramah adalah suatu metode penyampaian pesan secara lisan dan disertai dengan tanya-jawab. Media yang digunakan berupa sampah daun, briket bioarang, LCD, laptop, serta kamera digital. Penyuluhan berupa pengenalan sampah daun di pekarangan dan limbah pertanian berupa sekam padi serta dampaknya jika dibakar begitu saja dan pengenalan (pemberian materi) mengenai cara pembuatan briket bioarang. Setelah pemberian materi dilanjutkan dengan diskusi (tanya jawab).

\section{HASIL DAN PEMBAHASAN}

Kegiatan pengabdian masyarakat diawali dengan perkenalan narasumber. Selanjutnya penyampaian materi penyuluhan dengan metode ceramah.

1. Pembuatan briket bioarang dari sampah daun dan limbah pertanian berupa sekam padi

a. Karbonisasi

Karbonisasi (pengarangan) dapat dilakukan menggunakan drum bekas yang telah bersih dengan tinggi $85 \mathrm{~cm}$ dan diameter $55 \mathrm{~cm}$. Drum tersebut terlebih dahulu diberi lubang-lubang kecil dengan paku pada bagian dasar agar tetap ada udara yang masuk ke dalam drum, atau bisa juga dibuat lubang pada bagian tengah alas drum (diameter lubang $25 \mathrm{~cm}$ ). Selanjutnya seluruh bahan dimasukkan ke dalam drum dan api dinyalakan. Sekitar 10 menit akan terlihat mengepul asap putih dari atas drum yang menandakan bahwa pengarangan telah dimulai dari bagian dasar. Apabila menggunakan drum yang dilubangi bagian 
940 Penyuluhan Pemanfaatan Sampah Daun dan Limbah Pertanian Menjadi Briket Bioarang sebagai Sumber Energi Terbaru Ramah Lingkungan - Slamet Mardiyanto Rahayu, Rosalina Edy Swandayani, Arista Suci Andini, Hasan Basri, Syuhriatin, Baiq Diah Fitasari, Meilinda Pahriana Sulastri, Diah Meidatuzzahra

DOI: https://doi.org/10.31004/abdidas.v2i4.396

bawahnya maka drum harus diletakkan dalam posisi terbalik di atas tanah berpasir. Pasir diperlukan agar bagian bawah drum cukup rapat sehingga udara yang keluar masuk melalui bagian bawah drum dapat dihalangi. Selanjutnya daun kering dimasukkan ke dalam drum melalui lubang buatan dan dibakar.

Penyalaan awal dapat dilakukan dengan minyak. Selanjutnya, setelah api menyala sampah daun kering dimasukkan ke dalam drum sedikit demi sedikit agar nyala api tidak padam. Selama proses pembakaran harus dijaga agar tidak ada udara yang keluar masuk drum secara leluasa. Jika udara keluar masuk drum, maka pembakaran tidak menghasilkan arang melainkan abu.

Dalam proses pembakaran ini, api dan asap yang timbul akibat pembakaran di dalam drum menghalangi udara yang akan masuk melalui lubang buatan. Agar pembakaran merata, sebaiknya digunakan kayu untuk mengorek sampah/dedaunan yang dibakar di dalam drum. Pengisian dihentikan bila isi dapur atau drum sudah mencapai sekitar 1/3 tinggi drum. Jika asap yang keluar dari lubang buatan mengecil, ada dua kemungkinan yang terjadi yaitu apinya padam atau pembakaran sudah selesai. Untuk itu, drum dimiringkan sedikit (menggunakan kayu) agar udara masuk dari bawah dan segera ditegakkan kembali. Bila tidak keluar lidah api, berarti pembakaran sudah selesai. Jika pembakaran telah selesai maka siram drum dengan air.

Selanjutnya, drum digulingkan dan arang yang terbentuk dikorek-korek. Jika ditemukan bara arang yang menyala maka segera disiram lagi dengan air agar arang tersebut tidak menjadi abu. Kumpulkan arang yang terjadi dan simpan di tempat yang aman.

b. Penghalusan Arang

Setelah drum dingin, hasil pengarangan dituangkan di atas permukaan yang keras, datar, dan bersih. Selanjutnya arang digiling hingga sehalus mungkin. Penghalusan arang juga dapat dilakukan dalam ember menggunakan penumbuk. Untuk mendapatkan bahan briket bioarang yang bagus maka hasil penggilingan harus diayak.

c. Pencampuran dengan Bahan Perekat

Arang yang telah halus dicampurkan dengan bahan perekat sampai membentuk semacam adonan yang cukup kering. Bahan perekat ini dimaksudkan agar briket bioarang tidak mudah pecah atau rontok ketika dibakar. Pencampuran bahan briket dan bahan perekat atau lem dilakukan dalam sebuah wadah. Selanjutnya kedua bahan diaduk rata hingga membentuk adonan dan cukup lengket. Pencampuran bahan (arang) ke dalam larutan perekat dilakukan dengan perbandingan $600 \mathrm{cc}$ cairan lem/perekat dengan $1 \mathrm{~kg}$ bubuk arang kering. Adonan 
941 Penyuluhan Pemanfaatan Sampah Daun dan Limbah Pertanian Menjadi Briket Bioarang sebagai Sumber Energi Terbaru Ramah Lingkungan - Slamet Mardiyanto Rahayu, Rosalina Edy Swandayani, Arista Suci Andini, Hasan Basri, Syuhriatin, Baiq Diah Fitasari, Meilinda Pahriana Sulastri, Diah Meidatuzzahra

DOI: https://doi.org/10.31004/abdidas.v2i4.396

siap untuk dicetak atau dibentuk sesuai keinginan.

d. Pencetakan Adonan

Pencetakan adonan mulai dilakukan saat arang bisa digumpalkan. Bentuk cetakan disesuaikan dengan selera atau kebutuhan. Cetakan dapat terbuat dari pipa.

e. Pengeringan Briket

Briket yang telah terbentuk langsung dikeringkan di bawah sinar matahari agar briket tersebut cepat menyala ketika dinyalakan serta tidak berasap. Pengeringan dilakukan minimal 2 jam dibawah terik matahari yang terik. Setelah 2 jam (adonan mulai mengeras), bambu atau batang pisang dicabut pelan-pelan dengan sedikit diputar agar briket bioarang yang tercetak tidak pecah. Gulungan seng di sekelilingnya juga dibuka dengan cara dilepaskan kawat-kawat pengikatnya. Briket bioarang dijemur selama 2-3 hari sampai kering.

f. Pelapisan Bahan Penyala

Bahan penyala yang digunakan adalah minyak goreng bekas. Bahan penyala digunakan agar briket bisa menyala dalam waktu yang cukup lama. Pelapisan bahan penyala dilakukan setelah briket benar-benar kering, yang terlihat dari warna arang yang keabua-abuan. Briket yang akan dilapisi tersebut dicelupkan hingga larutan bahan penyala meresap jauh ke dalam arang karbon. Setelah itu, briket dijemur atau dikeringkan sekitar 2 jam sampai semua bahan penyala meresap dan tidak terlihat basah pada permukaannya.

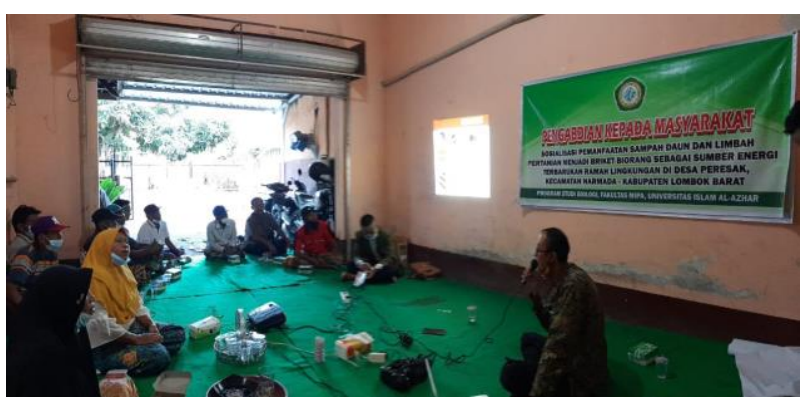

Gambar 1. Penyuluhan Pemanfaatan Sampah Daun dan Limbah Pertanian Menjadi Briket Biorang sebagai Sumber Energi Terbarukan Ramah Lingkungan di Desa Peresak, Kecamatan Narmada, Kabupaten Lombok Barat

2. Pengujian mutu briket bioarang dari sampah daun dan limbah pertanian berupa sekam padi.

Briket bioarang yang sudah kering bisa langsung diuji mutunya dengan cara dinyalakan. Jika bisa langsung menyala, tidak keluar asap, dan tidak terlihat retak-retak, berarti briket bioarang tersebut bermutu bagus dan layak disebut sebagai superkarbon.

3. Pengemasan produk briket bioarang yang telah dibuat.

Briket bioarang ini harus dikemas dengan baik dengan menggunakan plastik kedap udara. Tujuannya agar kondisi briket bioarang tetap kering. Setelah itu briket bioarang dikemas ulang dengan kotak karton atau kardus dan siap untuk didistribusikan kepada konsumen. 
942 Penyuluhan Pemanfaatan Sampah Daun dan Limbah Pertanian Menjadi Briket Bioarang sebagai Sumber Energi Terbaru Ramah Lingkungan - Slamet Mardiyanto Rahayu, Rosalina Edy Swandayani, Arista Suci Andini, Hasan Basri, Syuhriatin, Baiq Diah Fitasari, Meilinda Pahriana Sulastri, Diah Meidatuzzahra

DOI: https://doi.org/10.31004/abdidas.v2i4.396

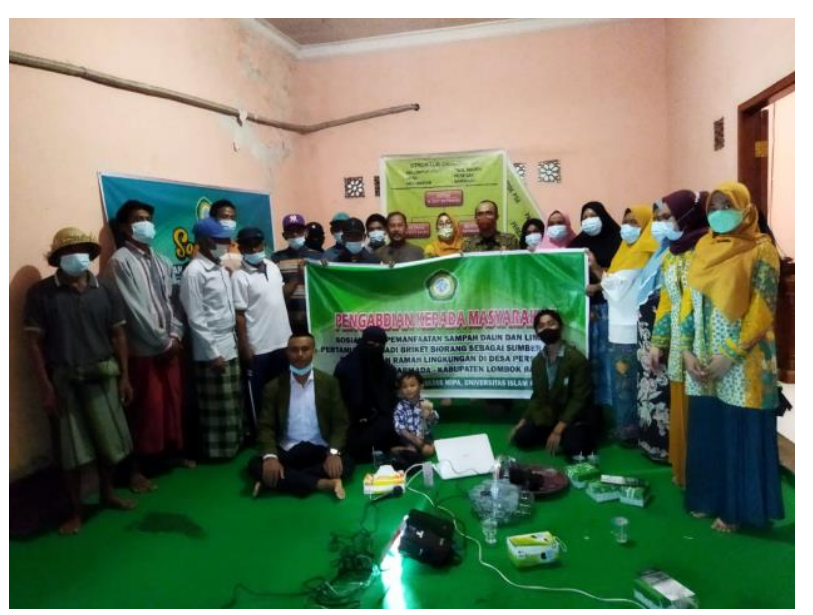

Gambar 2. Tim Pengabdian kepada Masyarakat dari Program Studi Biologi, FMIPA, Universitas Islam Al-azhar beserta Masyarakat Desa Peresak, Kecamatan Narmada, Kabupaten Lombok Barat

Hasil pengabdian masyarakat ini berupa meningkatnya pengetahuan dan keterampilan masyarakat dalam memanfaatkan limbah daun dan limbah pertanian menjadi briket sebagai sumber energi terbarukan yang ramah lingkungan. Hal ini terbukti dari banyaknya masyarakat yang antusias saat sesi diskusi (tanya jawab). Setelah kegiatan ini maka dapat disimpulkan bahwa perlu dilakukan pelatihan pembuatan briket bioarang kepada masyarakat Desa Peresak.

\section{SIMPULAN}

Melalui kegiatan pengabdian masyarakat ini, masyarakat Desa Peresak, Kecamatan Narmada, Kabupaten Lombok Barat memiliki tambahan pengetahuan untuk dapat mengurangi permasalahan lingkungan berupa tumpukan sampah daun dan limbah pertanian berupa sekam padi, mengurangi pencemaran udara, meningkatkan pengetahuan dan keterampilan masyarakat dalam pemanfaatan sampah daun dan limbah pertanian menjadi briket bioarang sebagai sumber energi terbarukan ramah lingkungan. Setelah kegiatan ini maka dapat disimpulkan bahwa perlu dilakukan pelatihan pembuatan briket bioarang kepada masyarakat Desa Peresak.

\section{UCAPAN TERIMA KASIH}

Terima kasih kepada Pemerintah Desa Peresak yang telah memberikan izin bagi terselenggarakannya kegiatan pengabdian kepada masyarakat ini dan kepada masyarakat di Desa Peresak, Kecamatan Narmada, Kabupaten Lombok Barat sehingga kegiatan pengabdian kepada masyarakat ini dapat berjalan dengan baik dan lancar. Terima kasih pula kepada Lembaga Penelitian dan Pengabdian kepada Masyarakat (LPPM) Universitas Islam Al-Azhar yang telah memberikan berbagai dukungan demi terselenggaranya kegiatan pengabdian kepada masyarakat ini.

\section{DAFTAR PUSTAKA}

Archenita, D., Atmaja, J., dan Hartati. 2010. Pengolahan Limbah Daun Kering sebagai Briket untuk Alternatif Pengganti Bahan Bakar Minyak. Rekayasa Sipil 6, 2, 87-95.

Hadiwiyoto, S. 2009. Penanganan dan Pemanfaatan Sampah. Jakarta: Idayu.

Hambali. E., Mujdalipah, S., Tambunan, A.H., Pattiwiri, A.W, dan R. Hendroko. 2007. Teknologi Bioenergi. Jakarta: Agro Media Pustaka.

Hardiatmi, S. 2011. Pendukung Keberhasilan Pengelolaan Sampah Kota. INNOFARM. Jurnal Inovasi Pertanian , 10, 1, 50-66.

Himawanto, D. A. 2003. Pengelohan Limbah Pertanian menjadi Biobriket Sebagai Salah 
943 Penyuluhan Pemanfaatan Sampah Daun dan Limbah Pertanian Menjadi Briket Bioarang sebagai Sumber Energi Terbaru Ramah Lingkungan - Slamet Mardiyanto Rahayu, Rosalina Edy Swandayani, Arista Suci Andini, Hasan Basri, Syuhriatin, Baiq Diah Fitasari, Meilinda Pahriana Sulastri, Diah Meidatuzzahra

DOI: https://doi.org/10.31004/abdidas.v2i4.396

Satu Bahan Bakar Alternatif. Laporan Penelitian. Surakarta: Universitas Sebelas Maret.

Riswan, Sunoko, H.R. 2011. Pengelolaan Sampah Rumah Tangga Di Kecamatan Daha Selatan. Jurnal Ilmu Lingkungan 9, 1, 31-39.

Sudarwanto, S. 2010. Peran Strategis Perempuan Dalam Pengelolaan Limbah Padat Bernilai Ekonomi. Jurnal EKOSAINS 2, 1, 65-74.

Sudiran. 2005. Instrumen Sosial Masyarakat Karangmumus Kota Samarinda Dalam Penanganan Sampah Domestik. Makara Sosial Humaniora 9, 1, 16-26.

Sumaryati. 2017. Program Briket Bioarang Sebagai Pengganti Bahan Bakar Alternatif Bagi Masyarakat Desa Pandowan. Jurnal Pemberdayaan 1, 1, 56-63.

Suprapto. 2005. Dampak Masalah Sampah Terhadap Kesehatan Masyarakat. Jurnal Mutiara Kesehatan Indonesia 1, 2, 1-4.

Suyono \& Budiman. 2010. Ilmu Kesehatan Masyarakat Dalam Kontek Kesehatan Lingkungan. Jakarta: EGC.

Yuliah, Y., Suryaningsih, S., dan K. Ulfi. 2017. Penentuan Kadar Air Hilang Dan Volatile Matter Pada Bio-Briket Dari Campuran Arang Sekam Padi Dan Batok Kelapa. Jurnal Ilmu Dan Inovasi Fisika 01, 01, 1115.

Yustinah dan Hartin. 2011. Adsorpsi Minyak Goreng Bekas Menggunakan Arang Aktif dari Sabut Kelapa. Yogyakarta.

Zamirza, F. 2011. Pembuatan Biopelet dari Bungkil Jarak Pagar (Jathropa curcas L.) Dengan Penambahan Sludge dan Perekat Tapioka. Skripsi. Bogor: Fakultas Pertanian Teknologi Pertanian, Institut Pertanian Bogor. 